\title{
MODELLING TRAVELLER'S GROUND ACCESS MODE CHOICE OF DUBAI INTERNATIONAL AIRPORT, UNITED ARAB EMIRATES
}

Khaula A. Alkaabi

United Arab Emirates University, Al Ain, UAE

\begin{abstract}
With increased demand for air travel, airports have become economic engines of the regional development that connect aviation systems with other modes of transportation facilitating the movement of people and cargo. Originating air passengers account for the majority of passenger trips to and from an airport and have different ground access needs. Since the air transportation is interrelated to ground transportation, studying ground access mode choice of airport users is a crucial part of airport management and system planning. The purpose of this study is to identify Dubai International Airport (DXB) ground access mode characteristics and users located in the United Arab Emirates (UAE), which has not been studied previously. Although there are many different modes of transportation serving the airport, yet personal vehicles are the main mode used to arrive to the airport. Binary logistic regression models are developed to evaluate access mode choice for originating air travelers focusing on the mix between private vehicle and public transportation system (taxi, limousine, bus network, and Dubai metro) using data collected specifically for this study. A total of 1012 air travelers were interviewed and completed the questionnaire in December 2014. Models result showed that access mode choice is significantly affected by different socio-economic characteristics of travelers including income, nationality, household size, vehicle ownership; and different trip characteristics that include number of travelers and how often air travelers use public transportation in their community.
\end{abstract}

\section{KEYWORDS}

Dubai International Airport, ground access mode, Binary logistic regression model, air passengers, car, public transportation

Associate Prof. Dr. Khaula A. Alkaabi: Geography \& Urban Planning Department, United Arab Emirates University; Email: Khaula.alkaabi@uaeu.ac.ae (Corresponding Author) 


\section{INTRODUCTION}

As per the statistics of Dubai airport authority, there was an $11.4 \%$ average growth rate of passengers in every year till 2014 and authority is expected 104 million passengers on 2020. With rapid development of Dubai's economy and associated growth in personal income, the ability of residents to travel abroad is increasing significantly, also the high number of immigrants in the country made the airport as a major transit hub for the passengers. As a result, travel demand and aviation activities at DXB are increasing, partly creating road congestion that might negatively impact airport users' travel time. Attracting the passengers to the public transportation is the one of the major challenge of Dubai government. Traffic jams are frequently occurring at Dubai streets, which cause to delay the passenger to reach the destination. In order to better manage ground traffic and further improve accessibility to DXB, it is crucial to identify the access mode choice for each air traveler since this group makes the majority of trips to and from the airport. The major aim of the study is to find the factors influencing ground access modes choice, characteristics of the passengers who use ground transportation to reach the airport and the share of each ground access mode.

Dubai's aviation sector contributes a total of US\$6.2 billion to Dubai's GDP based on 2010 estimates (Oxford Economics, June 2011). By 2020, the economic contribution of Dubai's aviation sector is anticipated to grow to 32\% of Dubai's' GDP with US\$45.4 billion (Oxford Economics, June 2011). Understanding the travel behavior of airport users will guide Dubai government through the planning process to achieve an effective and sustainable transport system diminishing traffic congestion and car dependency.

Although there are several studies related to ground access mode choice, there was no study empirically investigating DXB ground access mode choice and the factors influencing modes choice to DXB. Therefore, this study focuses on understanding the modal preferences, demographic characteristics, and trip characteristics of DXB users. In order to develop an effective ground access to the airport, we must first understand the factors shaping the current modes choice by the air travelers; and this study will enable us to achieve this understanding. And it was observed from the analysis of model that socioeconomic factors that include monthly income (MI), nationality (N), household size (HS), employment status (ES) are significant factors at 0.05 and age, travel time, travel cost, and trip purpose was found not to be significant indicators in the model. Due to that most of the travelers use their own vehicles as their main mode of transportation to reach the airport.

\section{LITERATURE REVIEW}

Airports are vital resource for contemporary living as they form an essential part of moving people and shipping goods around the world (Alkaabi et al., 2013; Alkaabi and Debbage, 2011 and 2007). Moreover, airports connect air travelers with other modes of transportation and hence can be seen as a node that is connected to ground travel and both can affect each other (Alhussein, 2011). Ground traffic problems such as traffic congestion can have a negative impact on the management of air traffic; therefore, airport administrators and authorities are more often facing problems related to ground traffic at and around their airports. According to Alhussein (2011) and Jou et al. (2011), managing ground traffic is important for travelers and airport administrators, where the quality of ground access to an airport can influence the demand for airport air services.

Several studies have investigated ground transportation use at large airports and synthesized strategies for improving the quality of public transportation access to airports (Akar, 2013; Choo et al., 2013; ACRP, 2008a, 2008b; Budd et al., 2011a, 2011b; de 
Neufville, 2006; Reynolds-Feighan and Button, 1999; Alkaabi, 2017). One of the earliest studies in this field was made by Ellis et al. (1974). They developed statistical models for air passenger airport ground access mode choice. In their study, they used travel time as a measure of airport accessibility. Other studies considered in modeling ground access mode choice additional factors such as the number of ground transportation service available and the proportion of airport users who decide to choose different ground transportation modes. For example, Harvey (1986) showed that air passengers were highly sensitive to travel time, particularly with increasing flight length. In addition, he showed that the number of pieces of luggage carried by travelers is another variable that played an important role in mode choice. Clark and Lam (1990) and; Pels et al. (2003) elaborate on that work and found that trip purpose, travel cost, origin residential area, and party size also plays a significant role in mode choice. Sangho et al. (2007) added income, age, occupation, and gender variables to those variables used previously in other studies. They studied ground access mode choice for two domestic airports in Korea, Daegu Airport and Gimpo Airport, and their model demonstrated that this array of variables were significantly different across airport access mode.

Mamdoohi et al. (2012) studied the behavior of air travelers in accessing Imam Khomeini International Airport (IKIA). They found that airport access mode choice is significantly affected by trip purpose, private car ownership, travel time, and monthly income. In addition, they found that business travelers tend to pay more to use private transport to access IKIA than non-business air travelers. Alhussein (2011) investigate the King Khaled International Airport access mode characteristics and users, and found that variables such as number of luggage, nationality and income, and travel access time significantly affect mode choice. Psaraki and Abacoumkin (2002) investigate the travel distance to determine the market segment for an access service. They found that the use of the private cars and taxis are the main mode for traveling to Athens International Airport; however, due to its higher cost the use of the taxis decreased in relation to increasing distance between trip origin and the airport.

Foote et al. (2007) focused on factors affecting the use of rail transit when they examined mode choice at two major airports in Chicago, Illinois. They found that the most important factors affecting transit use by actual rail users are cost, time and being close by. They found that less than $8 \%$ of the departing air travelers accessed Midway and O'Hare airports. Mandle et al. (2000) concluded that $10 \%$ to $15 \%$ is the maximum market share of public transport at airports in the United States. Sobienaik, et al. (1979) studied the access mode choice at Ottawa-Hull and vicinity in Canada and found that walking time and luggage handling are the significant variables for mode choice. Choo et al. (2013) found that variables such as travel time, gender, income, age, trip purpose, and occupation are significantly affect mode choice in Korea. Hess et al. (2007) found that the most significant variables are air fare, frequency flyer benefits, and access time.

Tsamboulas and Nikoleris (2008) conducted a survey to investigate willingness to pay to save time on trips to the Athens International Airport. Their findings show that the majority of air travelers are not willing to reduce their travel time to the airport by paying any amount of money. Their findings are based on that air travelers chose the modes that offer high level of services, and because they arrive early to the airport and thus have a lot of time to spend in the airport prior to their departure. Nevertheless, the study finds that business air passengers and those who travel to the airport utilizing their own cars or take a taxi are more willing to pay to reduce their travel time. They also found that air travelers are more willing to pay if the distance from the airport increases. 
Hess and Polak (2005) added choice of airline and airport, and found a complex set of connections between several factors, including in-vehicle access time and flight frequency. Jou et al. (2011) investigated air travelers' choice of mode for access to the Taoyuan International Airport in Taiwan. They found that in-vehicle travel time and travel cost are significant factors affecting ground access choice. Gupta et al. (2008) also considered the time factor in mode choice decision in their modeling of ground access mode choice for the New York City metropolitan region. They concluded that access cost and time, and travelers' socioeconomic characteristics are vital factors affecting the resulting mode choice when they studied the ground access mode choice for the New York City metropolitan region. They found that this factor is more significant for groups of passengers, in addition for frequent versus less frequent travelers (i.e., business and non-business travelers).

Tam et al. (2008) took the time variable on another dimension. Their study was the notion of a "safety margin" in mode choice to Hong Kong International Airport (HKIA). Their investigation revealed that business air travelers place a significantly higher value on both safety margin and travel time for their ground access to HKIA. They found that the dominant modes of access to the airport are rail services and buses, suggesting these services have been able to provide service regularity that meets safety margin concern of most air travelers. Koster et al. (2010:1) study the variability in estimates of the cost of access travel time for Dutch air Travelers. They found business travelers and non-business travelers are similar regarding costs allocated for access travel time observing "the costs of access travel time variability for business travelers are between 3-36\% of total access travel cost, and for non-business travelers between 3-30\%". Alkaabi (2017) has investigated access mode choice of airport employees to DXB and their willingness to car sharing, as well as has discussed the factors that influence them to use public transportation for commuting to their work at the airport. The study revealed that DXB employees were mostly sensitive to their income, nationality, employment status, car parking permit, and parking compensation in making mode choices; and that they are less interested to car share.

In summary, previous studies provide several and important observations and insights about the models used to analyze, and the factors that affect travelers' mode choice that are the starting point for the current study.

First, identifying explanatory variables is a critical process in developing airport ground access mode choice. Two main groups of factors were utilized in most of these studies. The first group of factors is the travelers' socioeconomic characteristics. As shown in the table, many scholars include factors such as gender, age, household average income, traveled party size, and level of education and occupation type. The second group of factors is related to the trip characteristics such as travel time and cost, walking distance, auto access, access time, and flight frequency. Many of these factors are utilized in this study to investigate the mode choice of DXB.

Second, most of these studies utilized discreet choice model such as binary logistic model, nested model, and multinomial logistic regression models among others. However, no specific recommendation or judgment about which model is more appropriate. Each model is utilized based on the number of modal choice analyzed in the study and the selected appropriate explanatory variables. 


\section{DUBAI INTERNATIONAL AIRPORT}

Dubai International Airport (DXB), located east of Dubai Emirate at Al Garhoud district as shown in Figure (1), is currently the MENA region's busiest aviation hub, with a $15.2 \%$ increase in passenger traffic between 2012 and 2013 (from 57.6 million to over 66.4 million passengers) ranking it tenth among worldwide airports (ACI, 2014). As the largest cargo hub in the region, it also handled over 2.4 million tons in 2013, more than all other GCC airports combined (ACI, 2014). DXB is linked to three access transportation modes including: private cars, taxis and limousines, and public transit services (bus and metro). The airport is linked to the city by intra-city roads including Road D89 and Road 91, and is connected to the other emirates through highway E311 (Mohammed Bin Zayed Road) and highway E11 (Al Ittihad Road). DXB is also served by the government owned Dubai Taxi Agency providing 24-hour service at all terminals. Dubai Metro operates two lines through or near the airport. Passengers can directly access Terminal 1 and Terminal 3 through the Red Line stations with daily services run from 6 am to $11 \mathrm{pm}$, except Friday from $1 \mathrm{pm}$ to $12 \mathrm{am}$. Passengers can be also connected to Terminal 2 through the Green Line station near the Airport Free Zone. Dubai airport buses, operated by Roads and Transportation Authority (RTA), are available daily for passengers at every terminal connecting them to the city center and over 80 hotels (RTA, n.d.). Despite the government efforts toward public transport services, the core issue for the current study is the decision made by travelers between private cars and public transportation.

Dubai is planned to be the leading tourism and business hub in the Middle East for attracting substantial numbers of visitors and business investors to the region. As a result, Dubai government has capitalized the airport annual passenger capacity from 60 million to 75 million passengers by January 2013 (Hofmann, 2012) and developed its national carrier fleet - Emirates Airlines - to cope up with continuous demand for air services. By November 2013, DXB handled more than 60 million passengers, a 47.4\% increase from 2009 with 40.9 million passengers (CAPA, n.d.). The recent Dubai successful bid to host World Expo 2020 is expected to revitalize the local economy and attract additional overseas tourists, generating further traffic movement at DXB and Dubai streets network. To better manage ground traffic at and around DXB, Dubai government needs to focus further on improving ground accessibility to the airport and extending airport connectivity to the rest of the Emirates.

Different modes of transportation from different cities in the country serve Dubai Airport. Table 1 shows the origin/destination of these modes as well as the cost of using each mode, the time required to arrive to the airport by each mode from its origin, and the distance traveled to arrive to the airport. The table shows that buses are the cheapest mode of transportation that can travelers use from other cities than Dubai to arrive to the airport, however it takes more time than the other modes. Within Dubai Emirate, Metro Dubai and Dubai buses are considered the cheapest modes to arrive to the airport; however, the metro is the fastest mode that can be used to arrive to the airport while the buses are the slower modes as shown in the table. On the other hand, Dubai Taxi and Uber services are more convenient and faster despite their higher riding costs. 


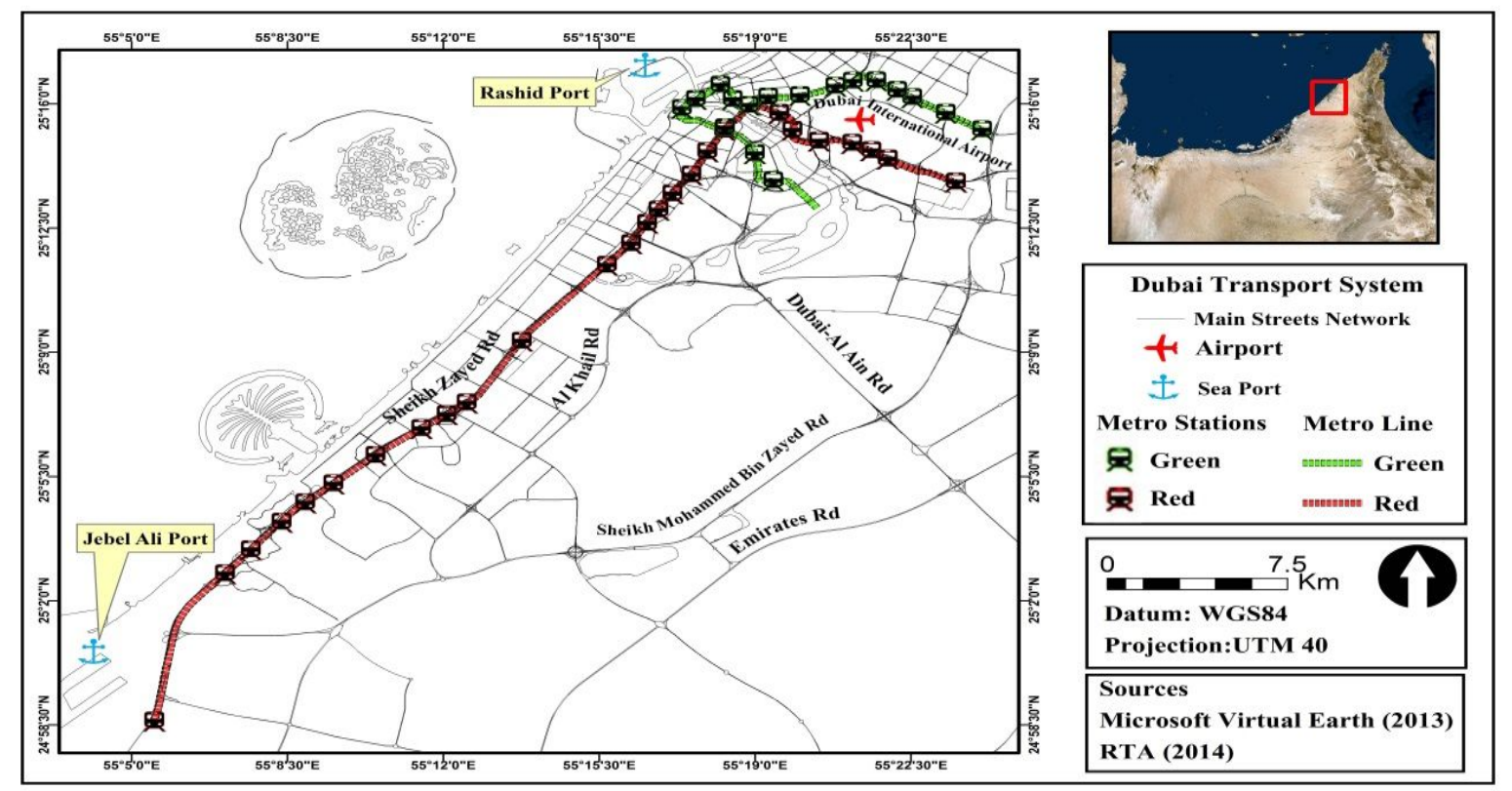

Figure 1: Locations of Dubai Transport Systems (Dubai International Airport, Dubai Metro, Main Streets Network, Sea Ports)

Table 1: Cost, time, and distance required for different modes of transportation serve DXB from different cities in the UAE

\begin{tabular}{|c|c|c|c|c|c|c|}
\hline $\begin{array}{c}\text { Origin } \\
\text { (Emirate) }\end{array}$ & Starting Point & $\begin{array}{c}\text { Destinati } \\
\text { on }\end{array}$ & $\begin{array}{c}\text { Mode of } \\
\text { Transport }\end{array}$ & $\begin{array}{l}\text { Cost } \\
\text { (AED) }\end{array}$ & Time & $\begin{array}{c}\text { Distan } \\
\text { ce }\end{array}$ \\
\hline \multirow{3}{*}{$\begin{array}{l}\text { Ras Al } \\
\text { Khaima }\end{array}$} & \multirow{3}{*}{ Khazam } & \multirow{3}{*}{ Terminal 1} & Taxi & 160 & $1 \mathrm{hr}$. & $\begin{array}{l}92.8 \\
\mathrm{~km}\end{array}$ \\
\hline & & & Bus & 25 & $2 \mathrm{~h}$ & $\begin{array}{c}92.8 \\
\mathrm{~km}\end{array}$ \\
\hline & & & Private Car & 400 & $1: 15 \mathrm{~h}$ & $\begin{array}{c}92.8 \\
\mathrm{~km}\end{array}$ \\
\hline \multirow[b]{2}{*}{ Ajman } & \multirow[b]{2}{*}{ Mohyat District } & \multirow[b]{2}{*}{ Terminal 1} & Taxi & 95 & $25 \mathrm{~min}$ & \multirow{2}{*}{$\begin{array}{l}26.5 \\
\mathrm{~km}\end{array}$} \\
\hline & & & $\begin{array}{c}\text { Private } \\
\text { Limousine }\end{array}$ & $140-200$ & $30 \mathrm{~min}$ & \\
\hline \multirow{2}{*}{ Al Ain } & \multirow{2}{*}{ Al Ain Bus Station } & \multirow{2}{*}{ Terminal 1} & Taxi & 400 & $1: 30 \mathrm{~h}$ & \multirow{2}{*}{$145 \mathrm{~km}$} \\
\hline & & & Bus & 20 & $2 \mathrm{~h}$ & \\
\hline \multirow{2}{*}{ Fujairah } & \multirow{2}{*}{$\begin{array}{l}\text { Fujairah Bus } \\
\text { Station }\end{array}$} & \multirow{2}{*}{ Terminal 1} & Taxi & 180 & $1: 30 \mathrm{~h}$ & \multirow{2}{*}{$107 \mathrm{~km}$} \\
\hline & & & Bus & 25 & $2: 15 \mathrm{~h}$ & \\
\hline \multirow{3}{*}{ Abu Dhabi } & \multirow{2}{*}{$\begin{array}{l}\text { Al Khaldiy Bus } \\
\text { Station }\end{array}$} & \multirow{3}{*}{ Terminal 1} & Taxi & 400 & $1: 26 \mathrm{~h}$ & \multirow{2}{*}{$130 \mathrm{~km}$} \\
\hline & & & Bus & $15-20$ & $2: 30 \mathrm{~h}$ & \\
\hline & Yas Mall & & Mini Van & 375 & $1: 11 \mathrm{~h}$ & $119 \mathrm{~km}$ \\
\hline \multirow{3}{*}{ Sharjah } & \multirow{2}{*}{ Rolla Bus Station } & \multirow{3}{*}{ Terminal 1} & Taxi & 70 & $30 \mathrm{~min}$ & \multirow{2}{*}{$26 \mathrm{~km}$} \\
\hline & & & Bus & 15 & $1: 30 \mathrm{~h}$ & \\
\hline & Dasman & & Uber & $55-65$ & $24 \mathrm{~min}$ & $\begin{array}{c}17.77 \\
\mathrm{~km}\end{array}$ \\
\hline Dubai & Burj Khalifa & Terminal 1 & Dubai Metro & 5 & $24 \min$ & $\begin{array}{c}14.2 \\
\mathrm{~km}\end{array}$ \\
\hline
\end{tabular}




\begin{tabular}{|c|c|c|c|c|}
\hline Palm Deira & & 3 & $21 \mathrm{~min}$ & $\begin{array}{l}6.55 \\
\mathrm{~km}\end{array}$ \\
\hline ADCB Station & & 5 & $14 \mathrm{~min}$ & $\begin{array}{l}7.65 \\
\mathrm{~km}\end{array}$ \\
\hline $\begin{array}{l}\text { Emirates } \\
\text { Exchange }\end{array}$ & & 7.5 & $50 \mathrm{~min}$ & $\begin{array}{l}55.8 \\
\mathrm{~km}\end{array}$ \\
\hline Burj Khalifa & \multirow{4}{*}{ Taxi } & 27.9 & $\begin{array}{c}16.82 \\
\min \end{array}$ & $\begin{array}{l}14.2 \\
\mathrm{~km}\end{array}$ \\
\hline Palm Deira & & 23.7 & $\begin{array}{c}20.70 \\
\min \end{array}$ & $\begin{array}{l}12.1 \\
\mathrm{~km}\end{array}$ \\
\hline ADCB Station & & 19.2 & $\begin{array}{c}13.32 \\
\min \end{array}$ & $9.8 \mathrm{~km}$ \\
\hline $\begin{array}{l}\text { Emirates } \\
\text { Exchange }\end{array}$ & & 89.8 & $\begin{array}{c}34.25 \\
\min \end{array}$ & $\begin{array}{c}45.8 \\
\mathrm{~km}\end{array}$ \\
\hline Burj Khalifa & \multirow{4}{*}{ Uber } & $44-55$ & $15 \mathrm{~min}$ & $\begin{array}{c}14.18 \\
\mathrm{~km}\end{array}$ \\
\hline Palm Deira & & $47-59$ & $18 \mathrm{~min}$ & $\begin{array}{c}15.18 \\
\mathrm{~km}\end{array}$ \\
\hline ADCB Station & & $35-43$ & $11 \mathrm{~min}$ & $\begin{array}{l}9.82 \\
\mathrm{~km}\end{array}$ \\
\hline $\begin{array}{l}\text { Emirates } \\
\text { Exchange }\end{array}$ & & $196-255$ & $35 \mathrm{~min}$ & $\begin{array}{c}47.22 \\
\mathrm{~km}\end{array}$ \\
\hline Burj Khalifa & \multirow{4}{*}{ Bus } & 5 & $35 \mathrm{~min}$ & $\begin{array}{c}18.86 \\
\mathrm{~km}\end{array}$ \\
\hline Palm Deira & & 5 & $47 \mathrm{~min}$ & $\begin{array}{l}6.95 \\
\mathrm{~km}\end{array}$ \\
\hline ADCB Station & & 5 & $38 \mathrm{~min}$ & $\begin{array}{l}8.04 \\
\mathrm{~km}\end{array}$ \\
\hline $\begin{array}{l}\text { Emirates } \\
\text { Exchange }\end{array}$ & & 7.5 & $1: 48 \mathrm{~h}$ & $\begin{array}{c}57.79 \\
\mathrm{~km}\end{array}$ \\
\hline
\end{tabular}

Sources: Data were retrieved by the author from the following: Uber, Wojhati, Careem, Dubai Airport, Al Hamrah Taxi, RTA, Sharjah Transportation, Ajman Taxi, Cars Taxi Fujairah, Al Ghazal Taxi, Google Earth.

\section{DATA COLLECTION}

In order to understand departing air travelers' travel behavior of ground access to DXB, a revealed preference (RP) face-to-face interview survey was designed and conducted by the author exclusively for this research at DXB in Dubai. Departing travelers, whose air journey origin was DXB, were targeted by the interview survey while connecting flight passengers were omitted. Departing travelers use ground access modes to arrive in the airport and encounter greater arrival time pressures to meet scheduled flight times, and the uncertainty of travel time to arrive in the airport.

The distribution method of the RP questionnaire survey was semi-random on departing air travelers, in the three terminals of DXB, sitting in the boarding waiting area. The RP survey collects information about traveler's actual choices to perform and utilize statistical models of travel mode choice. In the RP questionnaire survey, we asked the respondents about their current mode choice to arrive to DXB and the factors driving them to do that, in addition to different socio-economic characteristics of the travelers. The selection of survey participants was based on a systematic approach meaning that the first traveler sitting in the first row in the boarding waiting area was first given the questionnaire, and then the sixth traveler was selected, and so on. Travelers were selected from different nationalities and have different socio-economic characteristics and are residing inside the country and traveling outside. Six undergraduate students were trained to do the questionnaire and were 
distributed on the three terminals in the airport and were supervised by an assistant professor from the university during the survey period.

The questionnaire is comprehensive and requires 10 to 15 minutes for completion; therefore, seated air travelers at the boarding gates were interviewed to ensure the greater likelihood of a comprehensive response. A total of 1012 air travelers were interviewed and completed the questionnaire. The questionnaire survey was conducted in three days (28-30 December, 2014), and the sample size represents $0.03 \%$ of total departures on December. The survey was designed to satisfy the requirements for the development of a ground access mode choice behavior model and to explore the significant aspects, which affect the selection of ground access mode to travel to DXB. Since air travelers at DXB are from different nationalities, the questionnaire was designed and written in both English and Arabic languages. The questionnaire survey contains 36 questions divided into three parts. The first part was designed to collect information about the travelers' trip characteristics, while the second part was designed to collect general information regarding the selection of particular mode of transportation that traveler used to travel to/from the airport, and the third part consists of questions to collect general information about travelers' socioeconomic characteristics. As per the Dubai Statistics Center data, 70 million passengers used the Dubai airport among this 35.1 million departed and 34.9 million passengers arrived in Dubai. And it was observed that August, December, and January months were the peak time of passengers in Dubai airport

\section{DEMOGRAPHIC CHARACTERISTICS}

The analysis of the data revels that among the study sample, only $4.6 \%$ were UAE nationals and the rest are expatriates where Arab travelers (from the GCC and other Arabic countries) comprise a large proportion of the travelers (32.3\%) and the rest are from other parts of the world. As shown in Table (2), $91.2 \%$ are residents of the UAE; $58.2 \%$ of the respondents were male; about $80 \%$ of the total respondents were aged between 25 and 44 years where the largest age group of travelers was between 35 and 44 years old; $95 \%$ of the travelers do not have disability; more than $98 \%$ finished high school; $84.6 \%$ of them are working where $67.6 \%$ are full time and the majority were in professional/manager $(41.1 \%)$ followed by general office occupations (14.8\%). In terms of income, $33.6 \%$ had monthly income ranges between AED10,000 and AED14,999, showing a distinctive difference from other monthly incomes which exhibit percentages ranging from $2.1 \%$ to $16.2 \%$.

Table 2: Key socioeconomic characteristics of the sample

\begin{tabular}{|c|c|c|c|c|c|}
\hline \multicolumn{3}{|c|}{ Total Number of Respondents } & \multicolumn{3}{|c|}{1012} \\
\hline \multirow{7}{*}{ Nationality } & Total & 1009 & \multirow{5}{*}{$\begin{array}{l}\text { Number of } \\
\text { vehicles }\end{array}$} & Total & 1004 \\
\hline & UAE & $4.6 \%$ & & None & $22.5 \%$ \\
\hline & GCC & $12.1 \%$ & & 1 & $35.8 \%$ \\
\hline & Europe & $23.0 \%$ & & 2 & $30.7 \%$ \\
\hline & North American & $5.5 \%$ & & 3 or more & $11 \%$ \\
\hline & African & $8.2 \%$ & \multirow[b]{2}{*}{ Household size } & Total & 999 \\
\hline & $\begin{array}{l}\text { Arab (excluding } \\
\text { GCC) }\end{array}$ & $20.2 \%$ & & 1 & $17.6 \%$ \\
\hline
\end{tabular}




\begin{tabular}{|c|c|c|c|c|c|}
\hline & India & $9.8 \%$ & & 2 & $19.5 \%$ \\
\hline & Pakistan & $4.9 \%$ & & 3 & $17.0 \%$ \\
\hline & Filipino & $10.2 \%$ & & 4 & $32.6 \%$ \\
\hline & Other & $1.6 \%$ & & 5 or more & $13.2 \%$ \\
\hline \multirow{7}{*}{ Age } & Total & 1007 & \multirow{4}{*}{$\begin{array}{l}\text { Employment } \\
\text { statues }\end{array}$} & Total & 987 \\
\hline & $18-24$ & $2.3 \%$ & & Full time worker & $67.6 \%$ \\
\hline & $25-34$ & $30.3 \%$ & & Part-time worker & $16.8 \%$ \\
\hline & $35-44$ & $51.4 \%$ & & Not employed & $15.6 \%$ \\
\hline & $45-54$ & $15 \%$ & \multirow{6}{*}{ Education } & Total & 977 \\
\hline & $55-64$ & $0.9 \%$ & & $\begin{array}{l}\text { Did not finish high } \\
\text { school }\end{array}$ & $1.8 \%$ \\
\hline & $65+$ & $0.1 \%$ & & Finished high school & $4 \%$ \\
\hline \multirow{3}{*}{ Gender } & Total & 994 & & College & $23 \%$ \\
\hline & Male & $58.2 \%$ & & University & $56 \%$ \\
\hline & Female & $41.8 \%$ & & $\begin{array}{l}\text { Higher Education } \\
\text { (Master, PhD) }\end{array}$ & $15 \%$ \\
\hline \multirow{3}{*}{ Disable } & Total & 995 & \multirow{7}{*}{ Occupation } & Total & 1005 \\
\hline & Yes & $5.0 \%$ & & Not Working & $15.6 \%$ \\
\hline & No & $95.0 \%$ & & General Office & $14.8 \%$ \\
\hline \multirow{9}{*}{$\begin{array}{l}\text { Monthly } \\
\text { household } \\
\text { income } \\
\text { (AED) }\end{array}$} & Total & 850 & & Professional/Manager & $41.1 \%$ \\
\hline & Less than 5000 & $2.1 \%$ & & Sales/Services & $9.1 \%$ \\
\hline & $5,000-9,999$ & $16.2 \%$ & & Manufacturing & $8.5 \%$ \\
\hline & $10,000-14,999$ & $33.6 \%$ & & Other & $10.9 \%$ \\
\hline & $15,000-19,999$ & $12.7 \%$ & \multirow{5}{*}{ Resident or Visitor } & Total & 997 \\
\hline & $20,000-24,999$ & $3.9 \%$ & & Residents & $91.2 \%$ \\
\hline & $25,000-29,999$ & $8.6 \%$ & & Visitors & $8.8 \%$ \\
\hline & $30,000-34,000$ & $14.0 \%$ & & & \\
\hline & 35,000 or more & $8.8 \%$ & & & \\
\hline
\end{tabular}

\section{ACCESS AND TRANSPORTATION CHARACTERISTICS}

The majority of respondents (74.4\%) travel to Dubai airport are from Dubai and only $8.7 \%$, $8.3 \%$, and $8.5 \%$ of travelers are from Abu Dhabi, Sharjah, and other Emirates respectively as shown in Table (3). This indicates that the majority of airport users have the choice to use different mode of transportation to travel to the airport. About $77.5 \%$ of the respondents reported that they own at least one car which explains the high rate of using personal vehicles as the primary mode to travel to DXB. More than $50 \%$ of the respondents used their own cars to travel to the airport compared to $43.3 \%$ used taxis to arrive to the airport. The data reveals that the majority of the respondents are traveling in parties of two or more. Only $16.8 \%$ of the respondents were sole travelers. However, using the bus system or Dubai Metro accounted only for 3.8\% of the sample. Dubai Metro provides service 
within the Dubai city limits hence those who want to use the metro services reach the airport must use either of a bus, taxi or their private car and then travel to DXB. This process is time consuming and costly in terms of time and money. This also applies on those who are traveling to the airport from inside the City of Dubai. The table shows that $56.3 \%$ used the same mode of transportation to arrive to DXB during the past 12 months. As for trip purpose, about $65.5 \%$ of respondents were traveling for holiday and leisure and about $23.5 \%$ were traveling to visit friend or family and only $9.9 \%$ of the respondents were traveling for business purposes. In terms of using the airport parking, most of those who used the car to travel to the airport used the airport short term car park. However, only $20.6 \%$ of them were reimbursed fully or partially the parking cost. Large and small business are pillars of Dubai economy and these types of trips are reimbursed. Cross-tabulating parking reimbursement with trip purpose and parking period reveals that short-term business trips are reimbursed in higher percentage compared to other types of trips, followed by long-term business trips. $22.9 \%$ of the respondents travelled with one luggage and $21.9 \%$ of them carried two bags and the rest traveled with three pieces of luggage or more. Finally, a considerable percentage of the respondents $(32.5 \%)$ indicated that the primary factor of using their mode of transportation was journey time followed by parking charges (22.2\%).

Table 3: Key trip characteristics of the sample

\begin{tabular}{|c|c|c|c|c|c|}
\hline \multicolumn{4}{|c|}{ Total number of respondents } & \multicolumn{2}{|l|}{1012} \\
\hline \multirow{5}{*}{ Trip Origin } & Total & 997 & \multirow{5}{*}{$\begin{array}{l}\text { Number of } \\
\text { vehicles owned }\end{array}$} & Total & 1004 \\
\hline & Abu Dhabi & $8.7 \%$ & & None & $22.5 \%$ \\
\hline & Dubai & $74.4 \%$ & & 1 & $35.8 \%$ \\
\hline & Sharjah & $8.3 \%$ & & 2 & $30.7 \%$ \\
\hline & Other Emirates & $8.5 \%$ & & 3 or more & $11 \%$ \\
\hline \multirow{4}{*}{$\begin{array}{l}\text { Parking } \\
\text { charges }\end{array}$} & Total & 987 & \multirow{6}{*}{$\begin{array}{l}\text { Number of persons } \\
\text { traveling }\end{array}$} & Total & 1007 \\
\hline & Reimbursed in full & $16.3 \%$ & & 1 & $16.8 \%$ \\
\hline & Reimbursed partially & $4.3 \%$ & & 2 & $23.7 \%$ \\
\hline & None & $79.4 \%$ & & 3 & $23.9 \%$ \\
\hline \multirow{8}{*}{$\begin{array}{l}\text { Primary } \\
\text { factor } \\
\text { influencing } \\
\text { the choice of } \\
\text { ground } \\
\text { access mode }\end{array}$} & Total & 998 & & 4 & $18.2 \%$ \\
\hline & Cost & $11.7 \%$ & & 5 or more & $18.4 \%$ \\
\hline & Journey time & $32.5 \%$ & \multirow{7}{*}{$\begin{array}{l}\text { Airport access } \\
\text { mode }\end{array}$} & Total & 1010 \\
\hline & parking charges & $22.2 \%$ & & Car & $51.6 \%$ \\
\hline & luggage amount & $8 \%$ & & Taxi & $43.3 \%$ \\
\hline & $\begin{array}{l}\text { public transport } \\
\text { availability }\end{array}$ & $4.2 \%$ & & Limousine & $0.6 \%$ \\
\hline & nature of party & $1.9 \%$ & & Bus & $2.2 \%$ \\
\hline & Others & 19.4 & & Dubai Metro & $1.6 \%$ \\
\hline \multirow{2}{*}{$\begin{array}{l}\text { Number of } \\
\text { luggage }\end{array}$} & Total & 1006 & & Other & $0.8 \%$ \\
\hline & 1 & $22.9 \%$ & Purpose of the trip & Total & 1005 \\
\hline
\end{tabular}




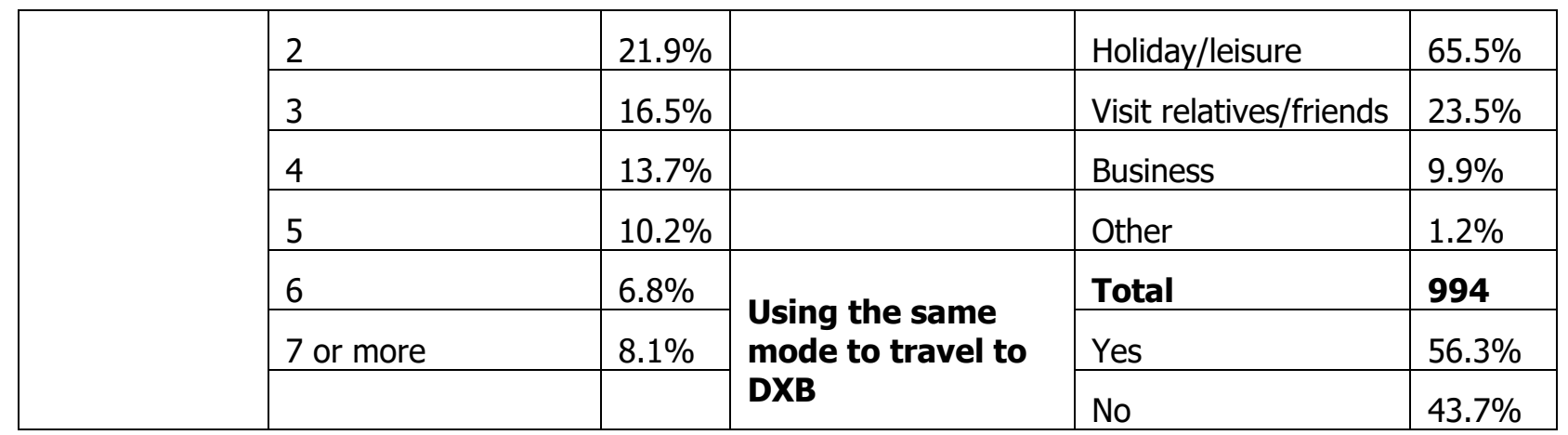

\section{DESCRIPTIVE ANALYSIS}

This section explores if key variables such as income, age, trip purpose, travel time, travel cost, and other explanatory variables affect ground access mode choice. Chi-square test was conducted to examine statistical difference among access modes related to socio-economic characteristics of travelers and trip characteristics. Airport access modes were classified into two different groups car and public transportation (combing taxi, limousine, bus, and metro) and excluding other modes due to insufficient sample size. To ensure reliability in performing the Chi-square test, some categories in the key variables are combined together so each cell in the cross-tabulation table have an expected count of five or more. Table 4 provides a cross-tabulation for access mode distribution by key variables related to both traveler and trip characteristics.

The table 4 shows that number of luggage is not a significant key variable that determine ground access mode to DXB. About $45 \%$ of travelers carried one or two bags in their journey and this percentage is same across all access modes. On the other hand, there are a strong association between the size of the party and the mode choice at .05 level $(P$-value $=.001)$. The data shows that $1.6 \%$ of travelers who use the metro to arrive to DXB are solo travelers, while more than $51 \%$ of those who use their private cars. In terms of trip origin, there is a significant association between access mode and the origin of the trip. The use of the car increases as the distance increases from DXB. The data shows that around $75 \%$ of trip is originating from Dubai, $8.7 \%$ from Abu Dhabi and $8.5 \%$ from Sharjah. Only 2.2 percentage of passengers use bus as their mode of transportation to reach the airport. Around $48 \%$ of passengers depend on the public transportation (combing taxi, limousine, bus, and metro) to reach the airport. And the data shows that the journey time is the one of the major reason for choosing the mode of transportation and followed by the parking charges.

Table 4: Chi-square test analyses of key variables by airport access mode

\begin{tabular}{|l|c|c|}
\hline & $X^{2}$-value & $P$-value \\
\hline \multicolumn{2}{|c|}{ Trip Characteristics } \\
\hline Number of luggage & 5.192 & 0.519 \\
\hline Number of people traveling & 16.419 & 0.003 \\
\hline Trip origin & 35.382 & 0.000 \\
\hline Traveling class & 9.986 & 0.007 \\
\hline
\end{tabular}




\begin{tabular}{|l|c|c|}
\hline Trip purpose & 12.814 & 0.005 \\
\hline Number of times traveled during the last 12 months & 18.611 & 0.001 \\
\hline Place to park the car & 35.732 & 0.000 \\
\hline Reimbursing parking fees & 33.182 & 0.000 \\
\hline Primary factor influencing the choice of mode & 54.489 & 0.000 \\
\hline How often traveler use public transportation & 205.530 & 0.000 \\
\hline \multicolumn{1}{|c|}{ Socio-Economic Characteristics } & 0.000 \\
\hline Nationality & 75.088 & 0.000 \\
\hline Age & 34.191 & 0.191 \\
\hline Gender & 1.707 & 0.000 \\
\hline Occupation & 83.741 & 0.000 \\
\hline Income & 52.580 & 0.000 \\
\hline Number of vehicles owned & 83.537 & 0.000 \\
\hline Household size & 142.768 & 0.000 \\
\hline Employment status & 63.318 & 0.000 \\
\hline Education & 25.131 &
\end{tabular}

Also, the data reveals that there are statistical differences in ground access mode in terms of trip purpose distribution. Private cars are mostly used in traveling to DXB regardless the purpose of the trip and particularly to visit friends or family members. On the other hand, most of those who use taxis or limousine to arrive to the airport travel for holiday or leisure purposes. The same implies on travelers who use the metro and bus system where more than $50 \%$ of those who use these systems travel for holiday or leisure purposes followed by business trips (22\%). Among those who used cars to travel to the airport, about $50 \%$ of respondents parked in the airport short term car park and only $10 \%$ parked in the airport long term car park. Parking charges was found to be a key factor that prevents many respondents to use their own cars particularly the long-term parking charges. At DXB, parking charges cost per day range between 100AED ( $\approx 30$ USD) to 240AED ( $\approx 65$ USD) which is more expensive than using other modes of transportation. Other key factors that determine the mode choice is the travel time and travel cost. The analyses shows that travel time and travel cost are important factors that would trigger some travelers to use their cars or taxi/limousine and avoid using the bus system or the metro.

In terms of the socio-economic characteristics and its influence on mode choice, the inspection of the entries in Table 4 shows that there is a strong association (sig $=0.000$ ) between mode choice and nationality, age, occupation, income, car ownership, Household size, employment status, and education. The analysis shows that most of the UAE nationals use their own car to travel to the airport and the Europeans are the least. This may due to high level of income of UAE nationals and at the same time the culture of using car in their daily lives. Europeans are more pronounced to use public transportation as the analysis show that $30 \%$ of Europeans use taxis and limousines and 35\% of them use the bus system or the metro to travel to Dubai airport. In terms of age, the table shows that age is a significant factor in mode choice. The majority of respondents who use the car are in the 24 
to 44 age group. Income is another key factor that influences mode choice. The entries of the table reveal that as the income increases the use of cars increases and the use of public transportation decreases. In addition, the data reveals that those who finished university, works full-time, professionals/managers, and own 2 cars are more willing to use cars in their journey to the airport.

\section{ACCESS MODE CHOICE MODELING}

\subsection{Model Specification}

Considering the current state of the transportation system in Dubai and the corresponding plans and programs, two alternative airport access modes were identified for accessing DXB, namely private car and public transportation (taxi, limousine, Dubai Metro, and bus system). Therefore, Binary Logit model is utilized for developing airport access mode choice model. Binary logit models were used with SPSS Software Version 22 and R statistical software due to their capabilities to characterize complicated factors of travel decisions of individuals. In addition, binary logit model has been widely used as a discrete choice model for airport access mode choice studies because it predicts the possibility of the occurrence of a specific event, based on the independent variables (see for example Alhussein, 2011, Mamdoohi, 2012). The use of this technique deepens the understanding of the mode choice behavior of travelers for ground airport access.

Extensive evaluation of the explanatory variables was taken place to design the mode choice model and to ensure the efficiency of the whole model. Explanatory variables for the model have been assessed to identify the variables which have most effectively augmented the data for mode access choice. Some of the variables (i.e., income, age, vehicle ownership) included in this study are considered substantial in modeling access mode choice. Other specific explanatory variables (such as nationality) that are predicted to have an impact on access mode choice are exclusively used in this study to deal with specific research problems. Overall, the explanatory variables used to model access choice mode are age (A), nationality (N), monthly income (MI), employment status (ES), Household size (HS), vehicle ownership (VO), number of travelers (NT), trip purpose (TP), travel time (TT), Travel Cost (TC), and how often travelers use public transportation (PT). These explanatory variables were found to have significant impacts on mode choice as shown in Table (5).

A binary logit model has been designed for two options mainly private cars and public transportation to compare the use of these travel modes as access modes to the airport. In order to compare the application of these travel modes and determine the factors that might impact the selection of certain mode. The dependent variable in this model is " 1 " for car use and " 0 " for public transportation use. Dummy variables have been created for the categorical variables in this model, for example: UAE Nationals has coded as "1" and other nationalities have been coded as " 0 " because of all the depended variables in the model is " 0 " for personal vehicle use and "1" for public transport use (i.e. from our survey it was observed that UAE nationals are Major percentage of personal vehicle users in Dubai, around $80 \%$ of UAE Nationals uses their own vehicles to reach airport). The insignificant explanatory variables in Table (5) were dropped from the model as well as other explanatory variables that does not affect directly on selecting a specific mode such as reimbursing parking fees that is not applicable in case of selecting public transportation. 
A binary logit models are estimated and calibrated to examine the impact of traveler socioeconomic characteristics and trip characteristics on travelers' access mode choice to DXB. The logit model is used mainly to predict a categorical variable from a set of predictor variables and it is based the random utility theory. This theory assumes that a utility value affects the decision of a traveler to select an alternative that achieves the highest utility. Therefore, the probability of selecting a particular alternative depends upon the utility gained from that alternative. In this study, the probability of selecting a specific mode $(I)$ to travel to DXB is equal to the probability that the utility of this mode $(I)$ is equal to or greater than the utility associated with alternative mode $(j)$. Therefore, the traveler will select the mode of transportation that yields the maximum utility. In this study, the utility comprises of traveler socio-economic characteristics, trip and mode attributes. Mathematically, the utility can be represented as in Equation 1:

$$
U_{\text {in }}=f\left(X_{\text {in }}, S_{\text {in }}\right)
$$

Where, $U_{\text {in }}$ is the utility obtained by air passenger $(n)$ selecting mode $(I)$. This equation indicates that the utility $U_{\text {in }}$ is a function (f) of the attribute value of mode $(I)$ in terms of traveler $(n)$ which is expressed as $X_{i n}$. $S_{i n}$ is the characteristic value of air passenger $(n)$ selecting mode $(I)$. Hence $U_{\text {in }}$ is considered to be random and cannot be measured with certainty (McFadden, 1974; Lerman, 1984; Ben Akiva and Lerman, 1985); therefore, it is rewritten as a sum of observed $\left(\mathrm{V}_{\mathrm{in}}\right)$ that relates to the access mode and the traveler, and unobserved or random $\left(\varepsilon_{\text {in }}\right)$ components as shown in Equation 2:

$$
U_{\text {in }}=V_{\text {in }}+\varepsilon_{\text {in }}=\beta_{n} X_{\text {in }}+\varepsilon_{\text {in }}
$$

Where $\beta_{n}$ is a vector of estimated parameters with regards to variable $X_{i n}$. Based on that and for this study, the binary logit model is governed by the following equations:

$$
\begin{aligned}
& U_{1 n}=\beta_{n} X_{1 n}+\varepsilon_{1 n} \\
& U_{2 n}=\beta_{n} X_{2 n}+\varepsilon_{2 n}
\end{aligned}
$$

Therefore, traveler $(n)$ select mode $(I)$ if the modes utility is greater than or equal to the other mode's $(J)$ utility as expressed in equation 5 :

$$
U_{\text {in }} \geq U_{\text {jn }}
$$

Therefore, the probability of mode ( $I$ ) to be selected is expressed in equation 6:

$$
\begin{aligned}
\operatorname{Pin}= & \left.\operatorname{Prob}\left(U_{\text {in }}>U_{j n}\right)=\operatorname{Prob}\left[\left(V_{\text {in }}+\varepsilon_{\text {in }}\right)>\left(V_{\text {jn }}+\varepsilon_{\text {jn }}\right)\right], i \neq j \text { where } j=1,2, \ldots\right] \\
= & \operatorname{Prob}\left[\varepsilon_{\text {jn }}<\left(V_{j n}-V_{i n}+\varepsilon_{\text {in }}\right)\right]
\end{aligned}
$$

To formulate a binary logit model, the probability can be expressed as in equation 7:

$$
P_{n 1}=\frac{\exp \left(\beta X_{1 n}\right)}{\exp \left(\beta X_{1 n}\right)+\exp \left(\beta X_{2 n}\right)}=\frac{1}{1+\exp \left(\beta X_{2 n}-\beta X_{1 n}\right)}=\frac{1}{1+\exp (\Delta U)}
$$

Where:

$\mathrm{P}_{\mathrm{n} 1}$ : is the probability that traveler $\mathrm{n}$ selects first mode;

$\beta X_{n 1}$ : is the utility function that traveler $n$ selects first mode;

$\beta X_{\mathrm{n} 2}$ : is the utility function that traveler $\mathrm{n}$ selects second mode;

$\Delta U=\beta X_{2 n}-\beta X_{1 n}=\sum\left(a_{i}-b_{i}\right) Z_{i}$, where $Z_{i}$ is the ith variable; $a_{i}$ is the coefficient of the ith variable in $\beta X_{n 1}$; bi is the coefficient of the ith variable in $\beta X_{n 2}$.

\subsection{Model Results and Discussion}

This section focuses on modeling DXB ground access mode choice using binary logit model. The explanatory variables used in this model consist of socio-economic variables (income, 
age, employment status, nationality, Household size, and vehicle ownership) and trip variables (travel cost and time, trip purpose, how often travelers use public transportation, number of travelers). All explanatory variables in the model are considered key variables affecting mode choice and were statistically significant at $P=0.05$ level as shown in Table (4). The model was calibrated to examine the behavior of air travelers in accessing DXB. Table (5) shows the results of the model for using private cars and public transportation as two different main groups of access mode choice to DXB. In general, the model shows that socio-economic factors that include monthly income (MI), nationality (N), Household size (HS), employment status (ES) are significant factors at 0.05 . On the other hand, trip variables that include how often travelers use public transportation and number of travelers are significant at 0.05 level. Age, travel time, travel cost, and trip purpose was found not to be significant indicators in the model. This finding coincides and contradicts with other findings found in the literature. For example, Alhussein (2011) found that number of luggage, income level, travel access time, and nationality had affected airport access mode choice in King Khaled International Airport (KKIA). Gupta et al. (2008) found that income, age, and gender are significant in airport access mode choice in New York City. Other scholars (see for example: Akar, 2013; Jou et al., 2011; and Choo et al., 2013) found that travel time, travel cost are the main factors influencing traveler's mode choice selection. In this study, travel time, travel cost was found not to be significant indicator due to that most of the travelers use their own vehicles as their main mode of transportation to reach the airport, and hence the other advantages of using the own vehicles such as privacy and comfortability of the cars may considered a primary factor of not looking at the cost of the travel. In addition, cars can be considered as a fast mode of transportation to reach the airport far area where the public transportation is away from the origin of journey. The calibrated model for the sample data is as follows:

$\operatorname{Ln}\left(P_{\text {car }} / P_{\text {public transportation }}\right)=4.915+0.753 \mathrm{VO}+0.909 \mathrm{HS}+0.866 \mathrm{MI}+0.086 \mathrm{~N}+1.950 \mathrm{NT}-$ $0.601 \mathrm{PT}+1.151 \mathrm{ES}$

Table 5: Model parameter estimates

\begin{tabular}{|l|c|c|c|c|c|c|c|c|}
\hline & & & \multirow{2}{*}{$\begin{array}{c}\text { Std. } \\
\text { error }\end{array}$} & Wald & df & Sig. & \multirow{2}{*}{$\operatorname{Exp}(\beta)$} & \multicolumn{2}{|c|}{$\begin{array}{c}\text { E5\% CI for } \\
\text { EXP( } \beta)\end{array}$} \\
\hline Number of vehicles owned & .753 & .281 & 7.199 & 1 & .007 & 20123 & 1.225 & 3.679 \\
\hline Household size & .909 & .461 & 3.879 & 1 & .049 & 2.482 & 1.004 & 6.132 \\
\hline Income & .866 & .0358 & 5.859 & 1 & .016 & 2.378 & 1.179 & 4.794 \\
\hline Nationality & .086 & .042 & 4.135 & 1 & .042 & 1.089 & 1.003 & 1.183 \\
\hline Number of travelers & 1.950 & .310 & 39.619 & 1 & .000 & 7.027 & 3.829 & 12.896 \\
\hline Trip purpose & -.109 & .094 & 1.346 & 1 & .246 & .897 & .746 & 1.078 \\
\hline Travel cost & -.183 & .229 & .635 & 1 & .425 & .833 & .532 & 1.305 \\
\hline Travel Time & .052 & .183 & .082 & 1 & .774 & 1.054 & .737 & 1.507 \\
\hline Age & .069 & .126 & .295 & 1 & .587 & 1.071 & .836 & 1.372 \\
\hline Employment & 1.152 & .400 & 8.308 & 1 & .004 & 3.164 & 1.446 & 6.923 \\
\hline Using public transportation & -.601 & .069 & 75.783 & 1 & .000 & .548 & .479 & .628 \\
\hline
\end{tabular}


Constant

4.915

.695

49.953

1

.000

136.266

Hosmer and Lemeshow Test shows that Chi-square-6.353, df- 8 and Sig-.608. Which indicates that the model fits the data as the significant value is greater than 0.05

Model Summary

-2 Log likelihood-785.577a, Cox \& Snell R Square- 0.333 and Nagelkerke R Square- 0. .444

The literature suggests that values of 0.2 to 0.4 for R2 represent an excellent fit (McFadden, 1979).

Table (6) indicates that the model is good in predicting the overall choice with $76.8 \%$ which indicate that the $76.8 \%$ of the variation of the dependent variable can be explained by the explanatory variables. Based on the outcomes' calculation of the classification matrices of predicted vs. observed outcomes, the model was found to accurately and correctly classify $76.4 \%$ of the car users and $77.1 \%$ of the public transportation users as shown in the table.

Table 6: Model Prediction

\begin{tabular}{|c|c|c|c|c|}
\hline \multirow{3}{*}{ Observed } & \multirow{3}{*}{ Observed } & \multicolumn{3}{|c|}{ Predicted } \\
\hline & & \multicolumn{2}{|r|}{ Mode } & \multirow{2}{*}{ Percentage Correct } \\
\hline & & Car & Public transportation & \\
\hline \multirow{2}{*}{ Mode } & Car & 298 & 92 & 76.4 \\
\hline & Public transportation & 94 & 317 & 77.1 \\
\hline \multicolumn{2}{|c|}{ Overall Percentage } & & & 76.8 \\
\hline
\end{tabular}

In this study, some of the socio-economic variables such as income, number of vehicles owned, Household size, nationality, and employment status have substantially contributed to explain the access mode choice. On the other hand, age have no significant contribution to explain the access mode choice. The coefficient for income were positive, which implies that increase in income results in increase in using personal vehicles over public transportation to reach the DXB. The results of the logit model shows that an increase for one unit increase in income value, while holding other variables constant, will result in increase of the preference for using car by 0.866 units. Figure (2a) shows the differences between various income groups based on the model and it clearly indicates that the increase of income reduces the probability of selecting public transportation. However, surprisingly the figure shows that the travelers whose monthly income is greater than AED 35,000 are willing to use public transportation more than other groups. This is due to that this category use limousines more than other group.

The model results show that nationality explains significantly access mode choice behavior. The nationality had a statically significant $p$-value $(p=.042)$ contributing to the explanation of access mode choice. Nationality has a positive sign and hence a positive impact upon choosing car mode over public transportation. Figure (2b) shows that being a United Arab Emirates national would decrease the probability of preferring public transportation to travel to DXB. On the other hand, being European increases the most the probability of using public transportation. In addition, the probability of selecting public transportation increases for nationalities other than being Emirates. 
Vehicle ownership is another explanatory variable that was found to explain significantly access mode choice. The positive sign of the coefficient implies that as the number of owned cars increases the probability of selecting public transportation decreases. However, Figure (2c) shows that those who do not own a car are less likely to use public transportation. The interpretation of this finding is that those travelers use the car as passengers to travel to the DXB. In terms of the Household size and its impact on access mode choice, the model shows that as the number of persons increases the probability of selecting car increases. Figure (2d) shows that if the household consists of one person, the probability of choosing public transportation increases and this probability decreases to almost the same degree as the household size increases.

How often travelers are using public transportation is obviously a major factor affecting access mode choice. As expected, travelers who use public transportation as their main mode of transportation are more likely to use this system to travel to DXB. Figure (3a) clearly shows that those who use public transportation in their daily commuting are more likely to use public transportation to travel to DXB. The estimated coefficient of the number of travelers also was found to explain significantly the access mode choice (see figure (3b)). Holding other variables constant, the increase in the number of travelers is expected to increase the probability of preferring cars to travel to DXB by 1.950 . The number of travelers is identified to be considerable and inversely impact the choice of choosing public transportation as the access mode to DXB. The probability of selecting public transportation decreases as the number of travelers (i.e., family or group trip) increases because the number of traveler's coefficient had a positive sign. It has been hypothesized that, when air passengers travel as a group to the airport they will select car mode over public transportation because of the superiority of the car mode in terms of privacy and comfort and the car mode gets more economical as the size of the travelers rises. Trip purpose, travel time, travel cost, and age were not found to have any significant contribution to explanation of access mode choice (see Table (6) and Figures (2f, 3c, d)) therefore they were eliminated from the model. 


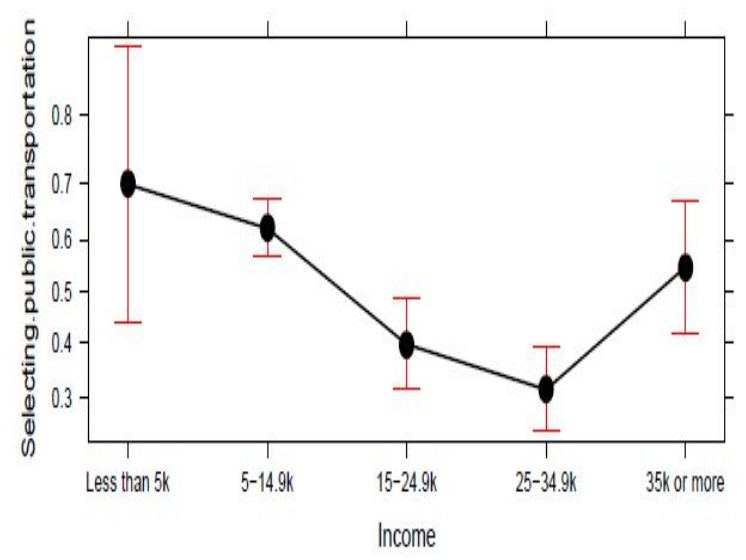

(a)

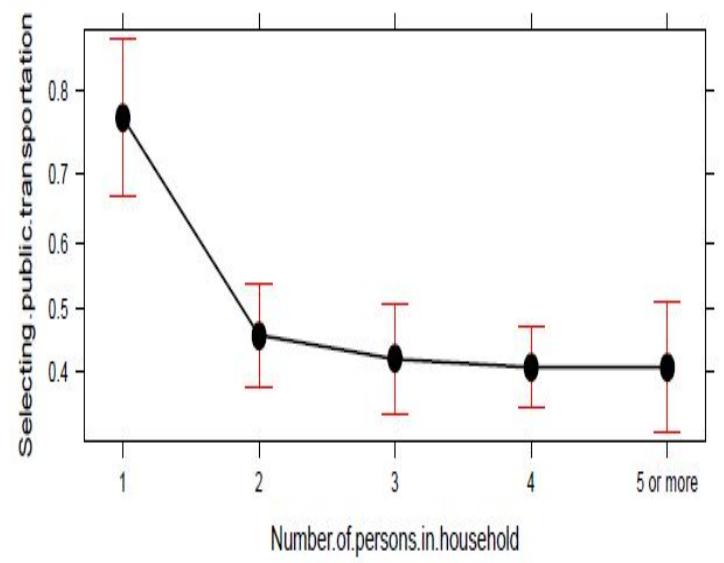

(d)

Figure 2: Probability of selecting access mode choice in terms of: a) Monthly income, b) nationality, c) vehicle ownership, d) Household size, e) employment, f) Age.

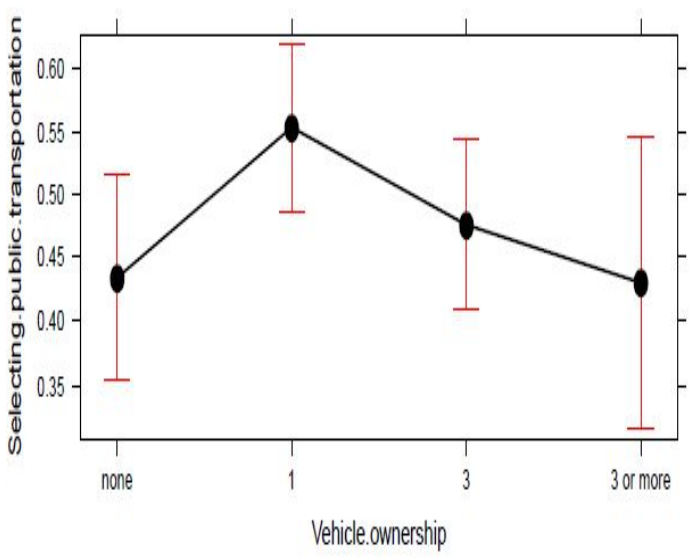

(c)
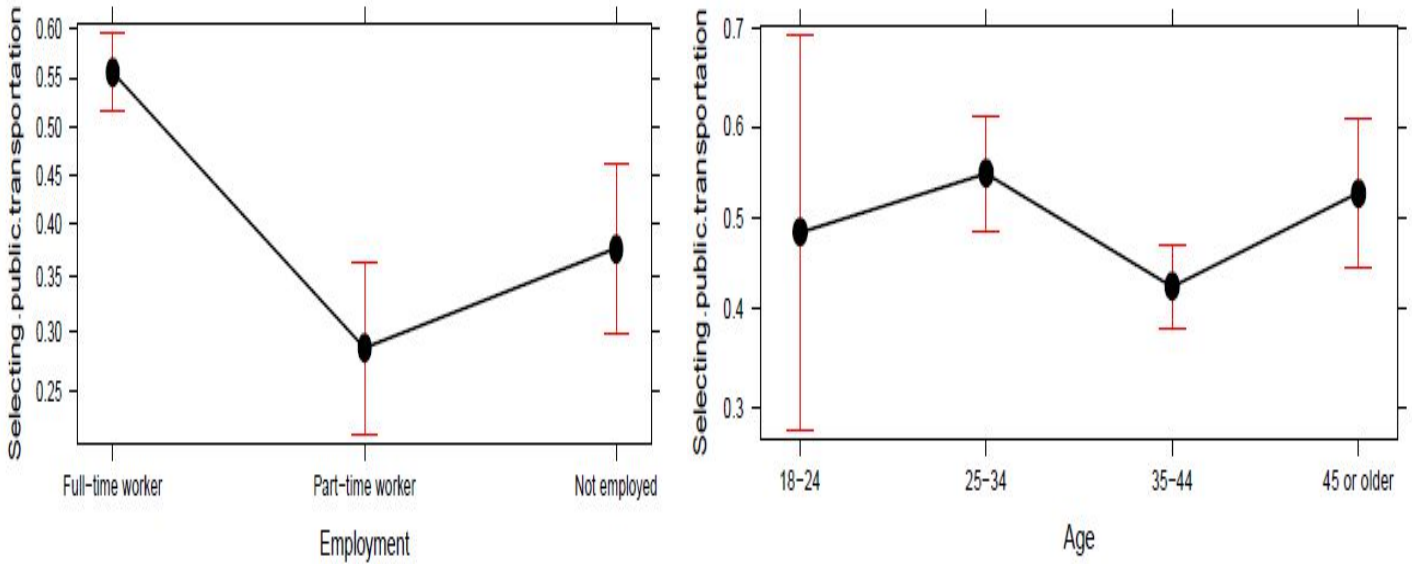

(f) 


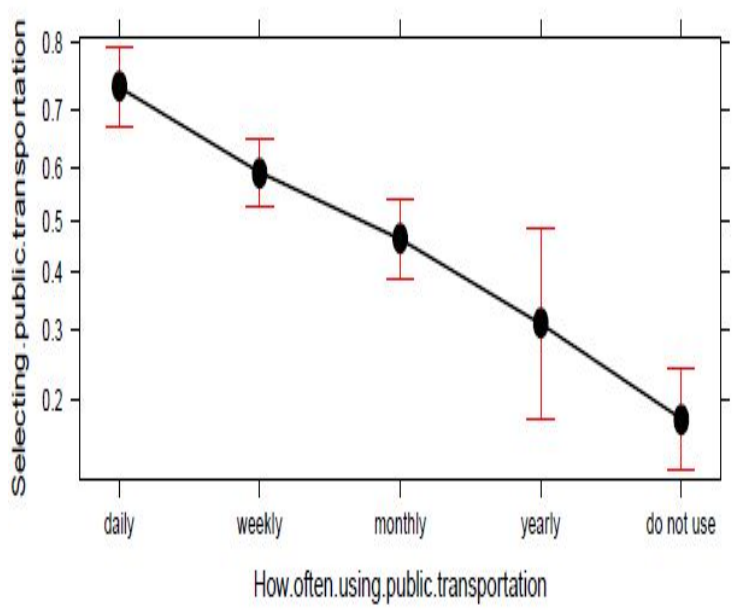

(a)

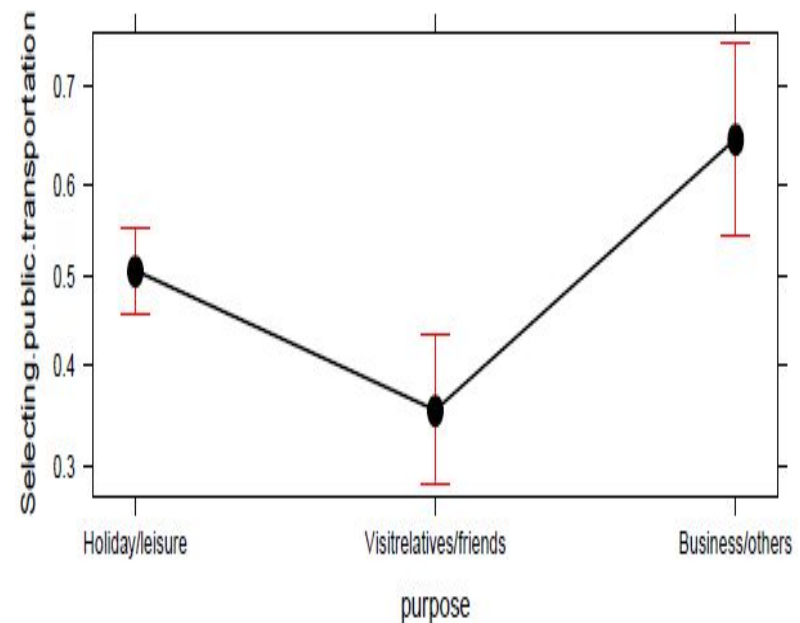

(c)

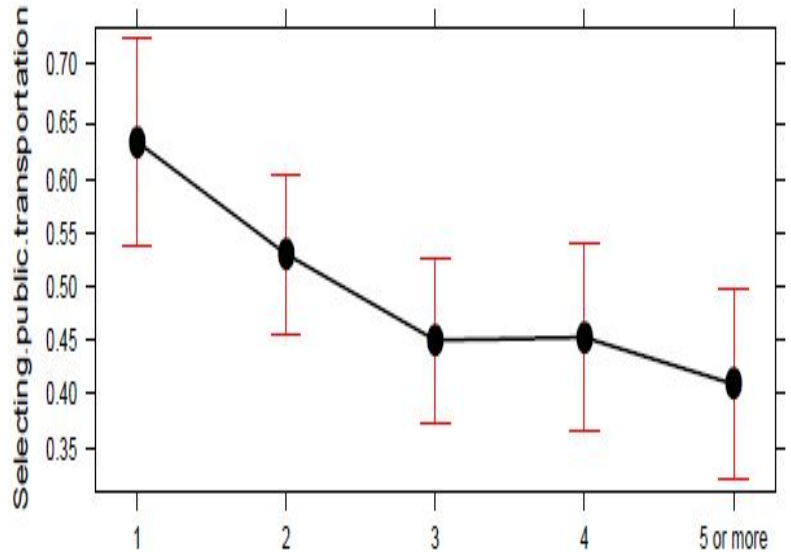

Numberofittravelers

(b)

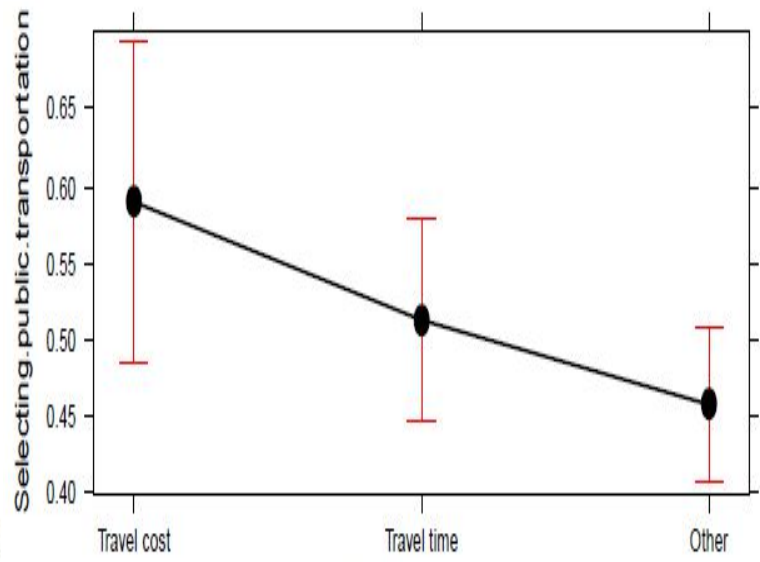

Travel.cost.and.time

(d)

Figure 3: Probability of selecting access mode choice in terms of: a) how often travelers use public transportation, b) number of travelers, c) trip purpose, and d) travel cost and time

\section{CONCLUSION AND RECOMMENDATIONS}

The main objective of this study was to explore access mode choice to DXB Travelers and trip characteristics, as well as access mode service to DXB were identified. Chi-square test was conducted to determine if some of the key socio-economic explanatory variables and trip explanatory variables are statistically different across access modes at DXB. Binary logistic models were proposed for two choice sets mainly private vehicles and public transportation considering the key explanatory variables. The model was calibrated and used to estimate 
effective explanatory variables. Model's result showed that access mode choice is significantly affected by different socio-economic characteristics of travelers including income, nationality, household size, vehicle ownership; and different trip characteristics that include number of travelers and how often air travelers use public transportation in their community. Variables such as age, trip purpose, and trip cost and time were found to have no impact on access mode choice. From these results it is very clear that the passengers are more concentrated on the comfort of travel instead of the travel time and travel cost. The authority can provide airport buses particularly for the air passengers which will help to attract the passengers to use public transportation. Authorities should take initiatives for the public awareness to use the public transportation for achieving a sustainable and smart transportation system of the city.

The model is beneficial to the planners because it is receptive to number of variables that affect access mode choice. Understanding the travel behavior of airport users should guide Dubai government through the planning process to achieve an effective and sustainable transport system diminishing traffic congestion and car dependency such as encouraging carpooling, park and ride, and increase bus trips or frequencies to the airport.

Dubai is a populated city that is supported to some extent with public transport, a city with hot climate during most of the year, and a high concentration of private cars. Most of the travelers to the airport depend on their vehicles to arrive to the airport as discussed earlier in this study. Therefore, there is a need to reduce the dependence and reliance on car use to travel to the airport. One way to do that is by encouraging travelers to use public transport more often. Metro Dubai appears to be a promising mean to carry more passengers to the airport since it is faster than other modes, and at the same time the cost of using this mode is cheaper. However, this mode does not cover the whole city. Transport authority must consider this point for the future expansion of the metro service in the city. So that it can help to shift the mode choices of passengers from personal vehicles to public transport.

The results of this study are beneficial to policy makers in different ways. First, public transit passengers originating outside and inside Dubai City should be promoted for accessing the airport by extending the Metro services within the city or to the other cities, and with the help of certain incentives. The aim is to promote public transit to be the main and preferred mode of transportation for Dubai airport access. These incentives can include increasing the public transit frequencies to the airport during peak- and off-peak periods and overnight. Second, giving the high percentage of travelers using their own cars to arrive to the airport, the transport authority in the city should consider establishing a loyalty program to attract more travelers onto public transportation. In addition, the transport authorities can build park and ride facilities and reimburse portion of the parking fees for those who use these facilities to park their cars and take public transportation to the airport. This reimbursement strategy may encourage those who do not use public transportation from inside Dubai City to use this system, and attract those who live outside the city by parking in these facilities and hence use public transportation. 
We recommend further investigation and extension of the current approach by determining the effect of travel seasons on airport ground access mode choice. In winter season, Dubai encounters some active tourism activities particularly from outside the country, while in the summer many of the residents in the city and nearby cities flew to different destinations around the globe. This can contribute in providing more information to transport operators in the city to improve their individual services and increase their share of the airport ground access market. In addition, more research should be conducted on business travelers as the timing of the survey was at the end of December where many travelers from different nationalities travel for leisure purposes or to visit their families in their original countries. Finally, the results show that $20.6 \%$ of travelers who use their own cars to arrive to the airport reimbursed fully or partially for the parking cost. This high percentage needs exploring. Reimbursing parking cost encourages travelers to use their own cars.

\section{FUNDING}

This research was supported by an internal grant provided by the College of Humanities and Social Sciences at the United Arab Emirates University (Fund No. G00002375).

\section{REFERENCES}

- ACI (2014). 2014 ACI Airport key performance indicators. [Online]. Available from: http://www.aci.aero/Data-Centre/Annual-Traffic-Data/Passengers/2013-final [Accessed 15 April 2015].

- ACRP (2008a). Ground Access to Major Airports by Public Transportation (ACRP REPORT 4). Project 11-02/Task 2. Transportation Research Board. National Research Council. [Online]. Available from: http://onlinepubs.trb.org/onlinepubs/acrp/acrp rpt 004.pdf [Accessed 4 January 2015].

- ACRP (2008b). Airport Ground Access Mode Choice Models: A Synthesis of Airport Practice (ACRP SYNTHESIS 5). Project 11- 03, Topic 03-02. Transportation Research Board. [Online]. Available from: http://onlinepubs.trb.org/onlinepubs/acrp/acrp syn 005.pdf [Accessed 4 January 2015].

- Akar, G. (2013). Ground access to airports, case study: Port Columbus International Airport. Journal of Air Transport Management, 30, pp.25-31.

- Alhussein, S. N. (2011). Analysis of ground access modes choice King Khaled International Airport, Riyadh, Saudi Arabia. Journal of Transport Geography, 19, pp.1361-1367.

- Alkaabi, K. A. (2017). Modeling Travel Choice Behavior of Airport Employees for Commuting to Work at Dubai International Airport, UAE. WIT Transactions on Ecology and the Environment: Sustainable Development and Planning VIII, 210, pp.577-589.

- Alkaabi, K. A., Debbage, K. G., and Bin Touq, A. (2013). The Promise of the Aerotropolis Model in the United Arab Emirates: The Role of Spatial Proximity and Global Connectivity. The Arab World Geographer, 16 (3), pp.289-312.

- Alkaabi, K. A. and Debbage, K. G. (2011). The Geography of Air Freight and Metropolitan Economic Performance: Some Potential Connections. Journal of Transport Geography 19, pp.1517-1529. 
- Alkaabi, K. A. and Debbage, K. G. (2007). Air Passenger Demand and Skilled Labor Markets by US Metropolitan Area. Journal of Air Transport Management, 13, pp.121-130.

- Basar, G. and C. R. Bhat. (2004). A Parameterized Consideration Set Model for Airport Choice: An Application to the San Francisco Bay Area. Transportation Research Part B, 38 (10), pp.889-904.

- Budd, T., Ison, S. and Ryley, T. (2011a). Airport surface access in the UK: a management perspective. Research in Transportation Business \& Management, 1, pp.109-117.

- Budd, T., Ison, S. and Ryley, T. (2011b). Airport surface access management: issues and policies. Journal of Airport Management, 6, pp.80-97.

- CAPA (n.d.). Dubai International Airport Traffic. [Online]. Available from: http://centreforaviation.com/profiles/airports/dubai-international-airport-dxb [Accessed 4 January 2014].

- Choo, A., Kim, I. and You, S. (2007). Exploring Characteristics of Airport Access Mode Choice in Korea. Transportation Research Board Annual Meeting.

- Choo, S., Youb, I. S. and Lee, H. (2013). Exploring characteristics of airport access mode choice: a case study of Korea. Transportation Planning and Technology, 36 (4), pp.335-351.

- Clark, M.C., Lam, and W.H.K. (1990). Airport ground access considerations. In: Airports into the 21st Century, Hong Kong Institution of Engineers, 5-7.

- de Neufville, R. (2006). Planning airport access in an era of low-cost airlines. Journal of the American Planning Association, 72, pp.347-356.

- Ellis, R.H., Bennett, J.C. and Rassam, P.R. (1974). Approaches for improving airport access. Transportation Engineering Journal, 100 (TE3), pp.661-673.

- Foote, P.J., LaBelle, S.J. and Stuart, D.G. (1997). Increasing rail transit access to airports in Chicago. Transportation Research Record, 1600, pp.1-9.

- Gosling, G. D. (1984). An Airport Ground Access Mode Choice Model. Technical Document, UCB-ITS-TD-84-6. Institute of Transportation Studies, University of California.

- Gupta, S., Vovsha, P. and Donnelly, R. (2008). Air passenger preferences for choice of airport and ground access mode in the New York city metropolitan region. Transportation Research Record: Journal of the Transportation Research Board 2042, pp.3-11,

- Harvey, G. (1986). Study of airport access mode choice. Journal of Transportation Engineering, 112 (5), pp.525-545.

- Hess, S. and Polak, J.W. (2005). Mixed logit modeling of airport choice in multi-airport regions. Journal of Air Transport Management, 11, pp.59-68.

- Hess, S., Adler, T. and Polak, J.W. (2007). Modelling airport and airline choice behavior with the use of stated preference survey data. Transportation Research Part E, 43, pp.221-233.

- Hofmann, K.c (2012). Dubai's Dedicated Emirates A380 Terminal to Open in 2013, Air Transport World.

- Jou, R., Hensher, D. and Hsu, T. (2011). Airport ground access mode choice behavior after the introduction of a new mode: a case study of Taoyuan International Airport in Taiwan. Transportation Research Part E, 47, pp.371-381. 
- Koster, P., Kroes, E. and Verhoef, E. (2010). Travel Time Variability and Airport Accessibility. Tinbergen Institute Discussion Paper. Tinbergen Institute Amsterdam. [Online]. Available from: https://papers.tinbergen.nl/10061.pdf [Accessed 4 January 2014].

- Mamdoohi, A.R., Saffarzadeh, M. Taherpour, A. and Yazdan Panah, M. (2012). Modeling Air Passengers' Ground Access Mode Choice a Case Study of IKIA. International Journal of Modeling and Optimization, 2 (2), pp. 147-152.

- Mandle, P.B., Mansel, D.M. and Coogan, M.A. (2000). Use of public transportation by airport passengers. Transportation Research Record, 1703, pp.83-89.

- Oxford Economics, (2011). Explaining Dubai's Aviation Model. [Online]. Available from: https://www.oxfordeconomics.com/my-oxford/projects/128910 [Accessed 4 January 2014].

- Pels, E., P. Nijkamp, and P. Rietveld., (1998). Access to Airports: A Case Study for the San Francisco Bay Area. Presented at 38th Congress of the European Regional Science Association, Vienna, 2-6.

- Pels, E., Nijkamp, P. and Rietveld, P. (2003). Access to and competition between airports: a case study for the San Francisco Bay Area. Transportation Research Part A, 37(1), pp.71-83.

- Psaraki, V. and Abacoumkin, C. (2002). Access mode choice for relocated airports: the new Athens International Airport. Journal of Air Transport Management, 8 (2), pp.89-98.

- Reynolds-Feighan, A.J. and Button, K.J. (1999). An assessment of the capacity and congestion levels at European airports. Journal of Air Transport Management, 5, pp.113134.

- RTA (n.d.). Dubai Airport Buses. [Online]. Available from: http://dubai-buses.com/ [Accessed 4 January 2014].

- Sangho, C., Ikki, K., So Young, Y., (2007). Exploring Characteristics of Airport Access Mode Choice in Korea. Transportation Research Board 86th Annual Meeting.

- Skinner, R. E. (1976). Airport Choice: An Empirical Study. Transportation Engineering Journal, 102 (4), pp.871-882.

- Sobieniak, J., Westin, R., Rosapep, T., and Shin, T. (1979). Choice of access mode to intercity terminal. Transportation Research Record, 728, pp.47-53.

- Tam, M. Ling and M. Lam, W.H.K. (2005). Analysis of airport access mode choice: a case study in Hong Kong. Journal of the Eastern Asia Society for Transportation Studies, 6, pp.708-723.

- Tsamboulas, D.A. and Nikoleris, A. (2008). Passengers' willingness to pay for airport ground access time savings. Transportation Research Part A: Policy and Practice 42, pp.1274-1282.

- TCRP, (2000). Improving Public Transportation: Access to Large Airports. Transportation Research Board. National Research Council. [online]. Available from: http://onlinepubs.trb.org/onlinepubs/tcrp/tcrp rpt 62-a.pdf [Accessed 4 January 2014].

- TCRP, (2002). Strategies for Improving Public Transportation Access to Large Airports. (TCRP REPORT 83). Transportation Research Board. National Research Council. [online]. Available from: http://onlinepubs.trb.org/onlinepubs/tcrp/tcrp rpt 83a.pdf [Accessed 4 January 2014]. 